\title{
Developing and Validating the Teacher Self-Efficacy for Teaching Students with Autism Spectrum Disorder (TSE-ASD) Scale
}

\author{
Nabi Nazari*
}

Department of Psychology, Faculty of Human Sciences, Lorestan University, Khorramabad, Iran

\begin{abstract}
Background: Autism spectrum disorder (ASD) continues to rise at an astonishing rate. As many schools attempt to create an inclusive environment conducive for students with autism to support academic success, we must recognize the teacher's role in creating an inclusive classroom. Using a student-specific teaching self-efficacy measure might provide more useful information for supporting teachers' beliefs for teaching students with ASD. Teachers with high self-efficacy have a positive impact on student achievement. The purpose of this investigation was to develop an instrument that can be used to measure teachers' self-efficacy for effectively working with students with ASD. The original version of the scale was translated and back-translated into Persian, followed by a pilot study. A sample $(n=633)$ of university students was recruited. Results indicated that the scale represented a unidimensional construct with acceptable internal consistency. Exploratory factor analysis demonstrated the unidimensionality of the TSE-ASD. The maximum likelihood confirmatory for the 12-item TSE-ASD model indicated excellent model fit indices $\left(x^{2} / d f=2.60\right.$, $\mathrm{CFI}=0.956, \mathrm{SRMR}=0.049$, PCLOSE $>0.05, \mathrm{RMSEA}=0.062,90 \% \mathrm{Cl}[0.052,0.082])$. As for criterion-related validity, The Pearson correlation coefficients between (TSE-ASD score) and self-regulation $(r=0.72, p<0.01)$ revealed a large correlation and linear regression indicating that TSE-ASD significantly predicted self-regulation, $b=0.69, p<0.001$. Using a student-specific teaching self-efficacy measure might provide more useful information for supporting teachers' beliefs for teaching students with ASD. The findings provide evidence that TSE-ASD is a reliable and valid instrument for assessing teacher self-efficacy for teaching students with Autism Spectrum Disorder in educational settings among Persian speaking individuals.
\end{abstract}

Keywords: Autism, Inclusive Education, Self-Efficacy, Validation, Intellectual Disability.

Intellectual disability is a disability characterized by significant limitations in intellectual functioning [reasoning, learning, problem-solving] and adaptive behavior, which covers a range of everyday social and practical skills [1]. This disability originates before the age of 18. Autism spectrum disorder [ASD] is a developmental disorder that affects social interaction and behavior. In 2019, one in 160 children has an autism spectrum disorder [ASD] [2]. The "spectrum" refers to the range of symptoms as well as their severity. Symptoms can include difficulties with speech, social communication and interaction, repetitive behavior, sensory issues, and hypersensitivity to stimuli. ASD may be diagnosed at any age. However, this condition is a "developmental disorder" because symptoms common most appear during the first two years of life. ASDs may significantly limit the capacity of an individual to conduct daily activities and participate in society. ASDs often negatively influence the person's educational and social attainments as well as employment opportunities [3].

Inclusive education is an approach that provides education to children with special educational needs in regular classrooms [4-6]. Inclusion provides the necessary support services in the same classroom.

*Address correspondence to this author at the Department of Psychology, Faculty of Human Sciences, Lorestan University, Khorramabad, Iran; Tel: +989197119027; Fax: +98-61-23986253; E-mail: Nazariirani@gmail.com
Research findings support the social and academic benefits of inclusive educational environments for students with disabilities [7-9]. The overarching assumption is that an inclusive approach to education will lead to improved student learning, engagement, and well-being, and better support for transitioning [10]. This applies to students with the diagnosis of ASD from early childhood through high school.

Fortunately, these benefits not only help the students with disabilities in a general education classroom, but they also benefit the students without disabilities (Kids Together INC nonprofit, 2009). Being in class with students who have disabilities facilitates working together and helping one another. Not only does this boost social interaction, but it also increases the opportunity to respect others and accept diversity. When inclusion is done correctly, with the necessary support(s), many benefits can be enjoyed by everyone involved (Kids Together INC nonprofit, 2009).

A lack of confidence in teaching students diagnosed with ASD is a serious barrier to educating these students in inclusive classrooms [11]. One central element preventing the progress of inclusive education has been teachers' attitudes and fears toward diverse learners. This fear is understandable as teachers feel they lack the necessary skills to teach children with special educational needs. Unfortunately, general 
education teachers feel ill-prepared to teach students diagnosed with ASD in inclusive classrooms at all grade levels [12-14]. Teachers in general education settings-both pre-service, report that they lack adequate understanding of students with ASD and how to teach them. That is, to successfully support the social and academic growth of students with ASD in inclusive educational placements, general education teachers need high levels of self-efficacy [15]. Evidence demonstrates that teachers with strong selfefficacy are more open to new ideas and more willing to try new teaching strategies to meet individual student needs [16].

The construct of self-efficacy emerged from Bandura's [17, 18] social cognitive theory. He suggested that individuals will pursue activities and situations where they feel competent and avoid situations in which they doubt their capacity to perform successfully. Self-efficacy is a well-documented predictor of behavior. Self-efficacy is defined as the expression of personal beliefs related to their capability to succeed in a specific behavior or to learn or perform a particular task [19] effectively. Self-efficacy plays a predicting and mediating role concerning individuals' achievement, motivation, and teaching [20]. Efficacy beliefs are directly associated with motivation [21], and professional commitment.

Furthermore, researchers have shown that teachers' beliefs are positively correlated with the learning outcomes of students with ASD [22-24]. Selfefficacy beliefs are context-specific judgments of one's capability to perform specific task context-specific achieve targeted outcomes. Teachers' self-efficacy is defined as "a judgment of their capabilities to bring about desired outcomes of student engagement and learning, even among those who may be difficult or unmotivated" [25]. Teachers who believe they can help their students learn are more likely to use positive instructional strategies and classroom management techniques and report higher levels of well-being [26, 27].

The purpose of this study was to develop and validate a teacher's self-efficacy instrument to measure teachers' self-efficacy for teaching students diagnosed with ASD in inclusive education.

\section{METHOD}

\section{Participants}

A sample of Afghan pre-service teachers was recruited from social media, utilizing a convenience method. A sample of 633 respondents (346 males; 287 females) aged between 20 and 39 participated (mean age $=30.14$ years; $S D=3.79$ years). The demographic characteristics of the sample are shown in Table 1. The inclusion criteria were being over the age of 18 years, being fluent in the Farsi( Dari) language, and being a teacher or university student. In total, 633 usable questionnaires were used in data analysis. Participants were ensured anonymity and confidentiality and were explicitly asked not to provide their names or other personal identification information. They were notified that they could decline their participation at any time.

\section{Measures}

Teachers' self-efficacy for teaching students with ASD (TSE-ASD); [28] was used to assess the TSEASD a 12-item measure assessing general self-efficacy for teaching all types of students. The scale features a 9-point Likert-type response format ranging from 1 (Nothing) to 9 (A great deal) with $\omega=.95$.

Self-regulation was measured with the 10-item SelfRegulation Scale, which used a response format

Table 1: Demographic Characteristics of the Sample $(\mathrm{N}=633)$

\begin{tabular}{|c|c|c|c|}
\hline Item & Value & Test & $p$ \\
\hline \multicolumn{4}{|l|}{ Categorical variables } \\
\hline \multicolumn{4}{|l|}{ Gender, $\boldsymbol{n}(\%)$} \\
\hline Women & $287(45.3)$ & \multirow[t]{2}{*}{$x^{2}=1.25$} & \multirow[t]{2}{*}{.16} \\
\hline Man & $346(54.7)$ & & \\
\hline \multicolumn{4}{|l|}{ Marital, $n$ (\%) } \\
\hline Single & $370(58.5)$ & \multirow[t]{2}{*}{$x^{2}=1.70$} & \multirow[t]{2}{*}{0.07} \\
\hline In Relationship & $263(41.5)$ & & \\
\hline
\end{tabular}

Note: $n=$ frequency; $\mathrm{y}=$ years; $\mathrm{M}=$ mean; $\mathrm{SD}=$ standard deviation. 
ranging from 1 (Not at all true) to 4 (Exactly true) with $\omega=.95$.

\section{Procedure}

\section{Ethics}

Ethics approval was granted by the research team's Institutional Review Board (IRB). The IRB reviewed the research protocol to ensure participant confidentiality, sampling, and obtaining informed consent.

\section{Development of the Survey}

Transcultural adaptation and content validity of the TSE-ASD was performed according to guidelines proposed by Beaton [29]. First, Two Persian translators independently translated the TSE-ASD from English to Persian. One of the translators was aware of the concepts being examined in the questionnaire being translated (psychologist). The other translator was neither aware nor informed of the concepts being quantified and had no medical or clinical background. To obtain a consensus version, an expert committee evaluated both versions to synthesize a consensual version. Then, a native English translator carried out a backward Persian-to-English translation of the consensual version, and this was subsequently compared with the original version. There were no major changes needed.

\section{Pilot Study}

In the final stage, a pilot study was performed with 30 participants to verify the scale's feasibility. The participant debriefing was performed to identify actual and potential linguistic, grammar, the ambiguity of the survey items, and the participants were requested to offer their feedback on every item. According to participant feedback, the survey items were easy to read and understand. The median response time was less than five minutes.

\section{Data Analysis}

All analyses were performed using SPSS version 25 (SPSS Inc., Chicago, IL) and AMOS version 24 with a two-sided $5 \%$ level of significance. Descriptive statistics were used to understand the participants' characteristics. Analyses of psychometric properties included CTT analysis and CFA model analysis. CTT analysis included internal consistency, test-retest reliability, corrected item-total correlation, average variance extracted (AVE), composite reliability, standard error of measurement, concurrent validity, and exploratory factor analysis (EFA). Exploratory factor analysis (EFA) was conducted to define the underlying structure among the variables in the analysis [30]. EFA was conducted on a randomized split of the data in the sample $(n=300)$. The 12 items of TSE-ASD were subjected to principal components analysis (PCA). Prior To performing PCA, Bartlett's test was conducted to test the hypothesis of sufficient correlation among the variables. Also, the KaiserMeyer-Olkin (KMO) was generated to measure sampling adequacy with 0.6 suggested $\mathrm{s}$ minimum value [30].

A maximum likelihood $(M L)$ confirmatory factor analysis (CFA) was then conducted on the remaining participants $(n=323)$. The following values demonstrate an excellent fitting model [31]: $1<x^{2} / d f<3$, comparative fit index $(\mathrm{CFI})>0.95$, root mean square error of approximation (RMSEA) < 0.06, and standardized root mean square residual (SRMR) < 0.06 . Criterion-related validity was evaluated by linear regression with respect to self-regulation.

\section{RESULTS}

There was no significant difference in the TSE-ASD scores between males and females $(t(631)=1.18$, $p=0.10)$. Convergent validity was tested utilizing average extracted variance (AVE> 0.50) [32]. The Cronbach alpha of the scale indicated acceptable internal reliability $(\alpha=0.88)$. Also, the Cronbach alpha if item deleted values and corrected item correlation values are shown in Table 2. The test-retest was evaluated by ICC. The ICC was 0.72 with $95 \% \mathrm{CI}$ $(0.52,0.8,9]$. The composite reliability was excellent $(C R=0.89)$. The convergent validity was acceptable $(\mathrm{AVE}=0.51 ; \quad \mathrm{AV} E<\mathrm{CR}$ ). The Pearson correlation coefficients between (TSE-ASD score) and selfregulation $(r=0.72, \quad p<0.01)$, and linear regression indicated that TSE-ASD significantly predicted selfregulation, $b=0.69, p<0.001$.

The Afghan TSE-ASD had acceptable dimensional quality. Principal component analysis (PCA) demonstrated the unidimensionality of the TSE-ASD. The KMO verified the sampling adequacy for the analysis $(\mathrm{KMO}=0.836$. Also, Bartlett's test of Sphericity was significant. The screen plot indicated one-factor for the targeted sample (see Figure 1). $(p<0.001)$. The one-factor had an eigenvalue of 5.4 , explaining $56 \%$ of the variance. 
Table 2: Item Statistics

\begin{tabular}{|c|c|c|c|c|c|}
\hline Item Number & $\begin{array}{c}\text { Squared multiple } \\
\text { correlation }\end{array}$ & $\begin{array}{c}\text { Corrected Item-Total } \\
\text { Correlation }\end{array}$ & Skew & Kurtosis & $\begin{array}{c}\text { Cronbach's If item } \\
\text { deleted }\end{array}$ \\
\hline \hline Q1 & 0.49 & 0.474 & 1.21 & 0.340 & 0.894 \\
\hline Q2 & 0.42 & 0.565 & 1.04 & -0.350 & 0.888 \\
\hline Q3 & 0.67 & 0.667 & 0.797 & -0.812 & 0.883 \\
\hline Q4 & 0.45 & 0.599 & 1.10 & -0.213 & 0.887 \\
\hline Q5 & 0.42 & 0.629 & 1.15 & -0.403 & 0.885 \\
\hline Q6 & 0.54 & 0.664 & 1.01 & -0.316 & 0.883 \\
\hline Q7 & 0.38 & .569 & 1.11 & -0.192 & 0.888 \\
\hline Q8 & 0.53 & 0.581 & 1.15 & -0.300 & 0.887 \\
\hline Q9 & 0.52 & 0.652 & 0.79 & -1.07 & 0.884 \\
\hline Q10 & 0.51 & 0.674 & 0.74 & -0.906 & 0.882 \\
\hline Q11 & 0.46 & 0.597 & 0.83 & -1.19 & 0.887 \\
\hline Q12 & 0.41 & 0.623 & 1.01 & 0.814 & 0.885 \\
\hline
\end{tabular}

Note: the provided in supplementary data.

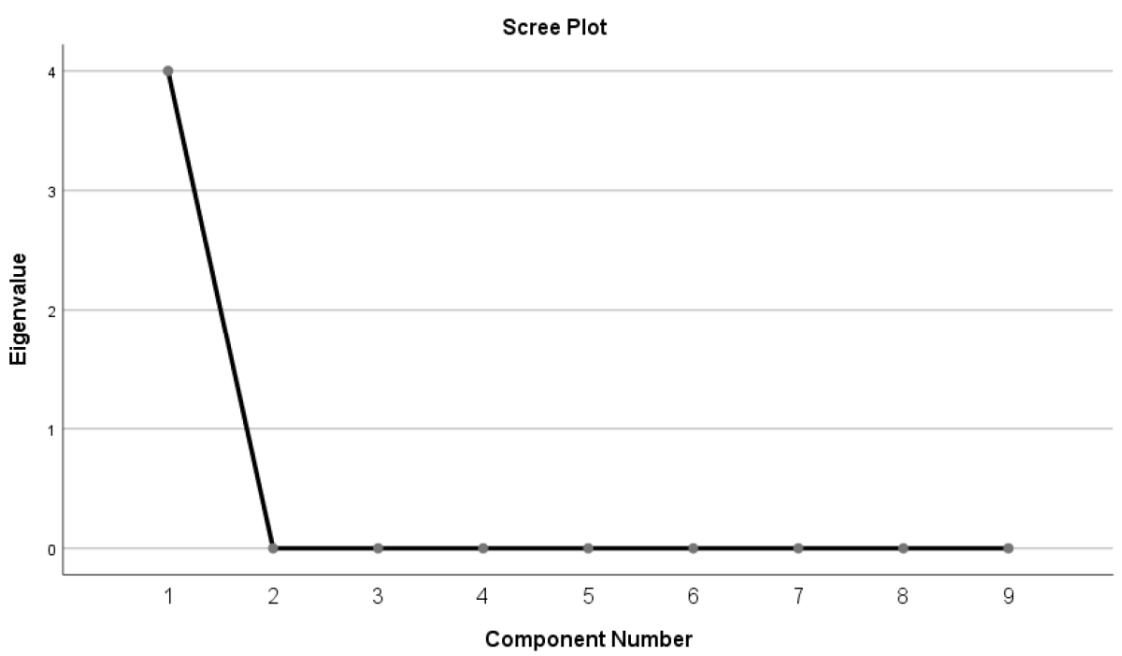

Figure 1: Scree plot.

The $M L$ confirmatory factor analysis (CFA) was performed to investigate the structural validity of the 12-item TSE-ASD construct. The CFA for the onefactor TSE-ASD model indicated excellent model fit indices $\quad\left(X^{2} / d f=2.81, \quad C F I=0.956, \quad S R M R=0.049\right.$, PCLOSE >0.05, RMSEA $=0.062,90 \% \mathrm{Cl}$ [0.052, 0.082]) See Figure 2.

\section{DISCUSSION}

The present study was designed to evaluate the validity and factor structure of the Persian TSE-ASD. The tool was also used to assess the teacher's selfefficacy for teaching students with an autism spectrum disorder. The study results demonstrated that TSEASD is a valid and reliable instrument for assessing teacher self-efficacy for teaching students with an autism spectrum disorder. It also had excellent internal consistency, because all the Cronbach's alpha values were well above the accepted range. The results demonstrated the TSE-ASD had a one-factor structure, and the findings were consistent with those of previous psychometric validation studies [28].

This scale can help school administrators know more about their teachers' beliefs specific to their students with ASD. If school administrators were to use this scale with their teachers, they could design interventions and support areas where teachers reported weakness or wavering beliefs. This instrument is not meant to be used as a screener or tool to identify when teachers are good or bad at teaching students 


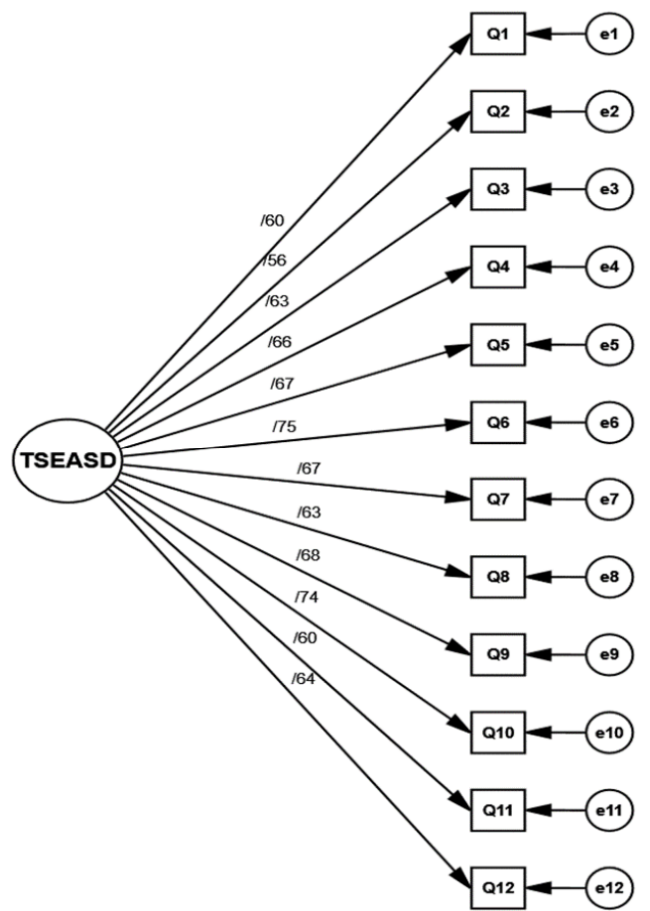

Figure 2: The unidimensional TSE-ASD.

with autism; instead, the scale can help teachers know more about what areas they believe they are competent and where improvements can be made. Knowing previous literature identified links between teacher self-efficacy and behavior, student achievement, and teacher factors like burnout [27], this construct can be a preventative measure to address some of these factors with teachers who work with this population of students. As teacher self-efficacy has been previously established as an important factor to consider when holistically looking at a teacher's effectiveness, this scale can help to address concerns specific to working with students with ASD. The instrument is not meant to be a qualifier for determining a "good" or "bad" teacher, but instead, a means of understanding what teachers believe, knowing the impact it can have on their teaching and their student's achievement.

The presence of special education certification is an important variable to investigate because previous research shows that teachers with specific preparation in special education have higher self-efficacy for inclusive teaching [33] and higher self-efficacy for teaching students with the diagnosis of ASD [12, 34]. Their findings suggest that general education teachers who had obtained some form of training in special education were likely to feel more positive and confident about teaching students with disabilities in their classrooms [33].

\section{CONCLUSION}

The findings provide evidence that TSE-ASD is a reliable and valid instrument for assessing teacher selfefficacy for Teaching Students with Autism Spectrum Disorder in educational settings among Persian speaking individuals.

\section{ABBREVIATION}

$$
\begin{array}{ll}
\text { TSE-ASD }= & \text { Teacher Self-Efficacy for Teaching } \\
& \text { Students with Autism Spectrum Disorder } \\
M & =\text { mean } \\
\text { SD } & =\text { standard deviation } \\
\text { EFA } & =\text { Exploratory factor analysis } \\
\text { AVE } & =\text { Average variance extracted } \\
M L & =\text { Maximum likelihood } \\
\text { CFA } & =\text { Confirmatory factor analysis } \\
\text { CR } & =\text { Composite reliability } \\
\text { CFI } & =\text { comparative fit index } \\
\text { TLI } & =\text { Tucker-Lewis index } \\
\text { RMSEA } & =\text { root mean square error of approximation } \\
\text { CI } & =\text { confidence interval } \\
\text { ICC } & =\text { Intraclass correlation coefficient }
\end{array}
$$

\section{REFERENCE}

[1] Tassé MJ, Luckasson R, Schalock RL. The relation between intellectual functioning and adaptive behavior in the diagnosis of intellectual disability. Intellect Dev Disabil 2016; 54(6): 381-390.

https://doi.org/10.1352/1934-9556-54.6.381

[2] Harrington JW, Allen K. The Clinician's Guide to Autism 2018; 35(2).

https://doi.org/10.1542/pir.35-2-62

[3] Hendricks D. Employment and adults with autism spectrum disorders: Challenges and strategies for success. J Vocat Rehabil 2010; 32(2): 125-134. https://doi.org/10.3233/JVR-2010-0502

[4] Connor MO, Quach J, Goldfeld S, Gold L, Aston R, Hopkins D. Approaches to the provision of educational support for children and young people with additional health and developmental needs 2015; (March 2019): 1-120.

[5] Brown EL, Craven RG, Mclean GF. Inclusive Education for Students With Intellectual Disabilities A Volume in International Advances in Education: Global Initiatives for Equity and Social Justice The Council for Research in Values and Philosophy.; 2015.

[6] Mcllvaine JA. Inclusive Education for Autistic Children: Helping Children and Young People to Learn and Flourish in the Classroom. J Autism Dev Disord 2020; 50(4): 1454-1455. https://doi.org/10.1007/s10803-019-04352-y 
[7] Fakolade O., Adeniyi S., Tella A. Attitude of teachers towards the inclusion of special needs in general education classrooms: the case of teachers in some selected schools in Nigeria. Int Electron J Elem Educ 2009; 1(3): 157-169.

[8] Nonis K, Chong W, Moore D, Tang H, Koh P. Pre-School Teacher's Attitudes towards Inclusion of Children with Developmental Needs in Kindergartens in Singapore. Int $\mathrm{J}$ Spec Educ 2016; 31(3): 1-30.

[9] Ismail Z, Basheer I, Khan JH. Teachers' Attitudes towards Inclusion of Special Needs Children into Primary Level Mainstream Schools in Karachi. Eur J Soc Behav Sci 2016; 17(3): 2177-2196.

https://doi.org/10.15405/ejsbs.195

[10] Ahsan MT, Sharma U, Deppeler JM. Inclusive Education for Students with Disability: A review of the best evidence in relation to theory and practice. Int J Whole Sch 2013; 4th(2): 18-30.

[11] Wynn TM. General education teachers' self-efficacy to teach autistic students in kindergarten through fourth-grade general education classrooms. Diss Abstr Int Sect A Humanit Soc Sci 2018; 79(12-A(E)): No-Specified. http: //ovidsp.ovid.com/ovidweb.cgi?T=JS\&PAGE $=$ reference\&D=p syc15\&NEWS=N\&AN=2018-48571-159.

[12] Barned NE, Knapp NF, Neuharth-Pritchett S. Knowledge and Attitudes of Early Childhood Preservice Teachers Regarding the Inclusion of Children With Autism Spectrum Disorder. J Early Child Teach Educ 2011; 32(4): 302-321. https://doi.org/10.1080/10901027.2011.622235

[13] Busby R, Ingram R, Bowron R, Oliver J, Lyons B. Teaching Elementary Children with Autism. Rural Educ 2018; 33(2): 27-35. https://doi.org/10.35608/ruraled.v33i2.416

[14] Doody O, Connor MO. TP-Placements \& Beliefs-Intellectual Disability-Doody \& O'Connor 2012[1].pdf 2012.

[15] Sharma U, George S. Understanding teacher self-efficacy to teach in inclusive classrooms. Asia-Pacific Perspect Teach Self-Efficacy 2016; (1997): 37-51. https://doi.org/10.1007/978-94-6300-521-0 3

[16] Lindsay $S$, Proulx $M$, Scott $H$, Thomson N. Exploring teachers' strategies for including children with autism spectrum disorder in mainstream classrooms. Int $\mathrm{J} \mathrm{Incl} \mathrm{Educ}$ 2014; 18(2): 101-122.

https://doi.org/10.1080/13603116.2012.758320

[17] Bandura A, Barbaranelli C, Caprara GV, Pastorelli C. Multifaceted Impact of Self-Efficacy Beliefs on Academic Functioning. Child Dev 1996; 67(3): 1206-1222. https://doi.org/10.1111/j.1467-8624.1996.tb01791.x

[18] Zimmerman BJ, Bandura A, Martinez-Pons M. SelfMotivation for Academic Attainment: The Role of SelfEfficacy Beliefs and Personal Goal Setting. Am Educ Res J 1992; 29(3): 663-676. https://doi.org/10.3102/00028312029003663

[19] Zimmerman B, Kitsantas A. Reliability and validity of selfefficacy for learning form (SELF) scores of college students. J Psychol 2007; 215(3): 157-163.

https://doi.org/10.1027/0044-3409.215.3.157

[20] Ayllón S, Alsina Á, Colomer J. Teachers' involvement and students' selfefficacy: Keys to achievement in higher education. PLoS One 2019; 14(5): 1-11. https://doi.org/10.1371/journal.pone.0216865
[21] Ryan RM, Deci EL. The Psychology of Self-Determination 1982; (May). https://doi.org/10.2307/2067164

[22] Segall MJ, Campbell JM. Factors influencing the educational placement of students with autism spectrum disorders. Res Autism Spectr Disord 2014; 8(1): 31-43. https://doi.org/10.1016/j.rasd.2013.10.006

[23] Emmers E, Baeyens D, Petry K. Attitudes and self-efficacy of teachers towards inclusion in higher education. Eur $\mathrm{J}$ Spec Needs Educ 2020; 35(2): 139-153. https://doi.org/10.1080/08856257.2019.1628337

[24] You S, Kim E, Shin K. Teachers' Belief and Efficacy Toward Inclusive Education in Early Childhood Settings in Korea. Sustainability 2019; 11(5): 1489. https://doi.org/10.3390/su11051489

[25] Zee M, Koomen HMY, Jellesma FC, Geerlings J, de Jong PF. Inter- and intra-individual differences in teachers' selfefficacy: A multilevel factor exploration. J Sch Psychol 2016; 55: 39-56

https://doi.org/10.1016/j.jsp.2015.12.003

[26] Nazari N, Far DM. The Relationship between Teaching Skills, Academic Emotion, Academic Stress and Mindset in University Student Academic Achievement Prediction: A PLS-SEM Approach. J Intellect Disabil - Diagnosis Treat 2019; 7(3): 119-133 https://doi.org/10.6000/2292-2598.2019.07.03.9

[27] Zee M, Koomen HMY, Jellesma FC, Geerlings J, de Jong PF. Inter- and intra-individual differences in teachers' selfefficacy: A multilevel factor exploration. J Sch Psychol 2016; 55: 39-56. https://doi.org/10.1016/j.jsp.2015.12.003

[28] Love AMA, Toland MD, Usher EL, Campbell JM, Spriggs AD. Can I teach students with Autism Spectrum Disorder? Investigating teacher self-efficacy with an emerging population of students. Res Dev Disabil 2019; 89(January): 41-50. https://doi.org/10.1016/j.ridd.2019.02.005

[29] Beaton DE, Bombardier C, Guillemin F FM. Guidelines for the Process of Cross-Cultural Adaptation of Self-Report Measures. Spine (Phila Pa 1976) 2000; 25(24): 3186-3191. https://doi.org/10.1097/00007632-200012150-00014

[30] Tabachnick BG, Fidell LS. Using Multivariate Statistics Barbara G. Tabachnick, Linda S. Fidell.; 2014.

[31] Hu LT, Bentler PM. Cutoff criteria for fit indexes in covariance structure analysis: Conventional criteria versus new alternatives. Struct Equ Model 1999; 6(1): 1-55. https://doi.org/10.1080/10705519909540118

[32] Henseler J, Hubona G, Ray PA. Using PLS path modeling in new technology research: Updated guidelines. Ind Manag Data Syst 2016; 116(1): 2-20.

https://doi.org/10.1108/lMDS-09-2015-0382

[33] Sokal L, Sharma U. Canadian in-service teachers' concerns, efficacy, and attitudes about inclusive teaching. Except Educ Int 2013; 23(1): 59-71.

[34] Humphrey N, Symes W. Inclusive education for pupils with autistic spectrum disorders in secondary mainstream schools: Teacher attitudes, experience and knowledge. Int J Incl Educ 2013; 17(1): 32-46. https://doi.org/10.1080/13603116.2011.580462

\section{DOI: https://doi.org/10.6000/2292-2598.2020.08.04.10}

(c) 2020 Nabi Nazari; Licensee Lifescience Global.

This is an open access article licensed under the terms of the Creative Commons Attribution Non-Commercial License (http://creativecommons.org/licenses/by-nc/3.0/) which permits unrestricted, non-commercial use, distribution and reproduction in any medium, provided the work is properly cited. 